\title{
КОРПОРАТИВНАЯ КУЛЬТУРА СОТРУДНИКОВ КОМПАНИИ В СФЕРЕ ЛОГИСТИКИ В УСЛОВИЯХ ПАНДЕМИИ COVID-2019
}

\section{CORPORATE CULTURE OF THE COMPANY'S EMPLOYEES IN THE FIELD OF LOGISTICS IN THE CONTEXT OF THE COVID-2019 PANDEMIC} O. Devletov
K. Gvozdeva
T. Sazbandyan

Summary: The descriptive analysis of changes in the logistics services market caused by the global pandemic, carried out in the article, allowed us to establish trends that will determine the activities of logistics companies in the future with an uncertain temporal framework, as well as in the post-pandemic period. It is shown that such changes require an adequate transformation of the corporate culture of employees, which has a significant impact on the stability and consistency of the functioning of the enterprise in rapidly changing market requirements. It is determined that reengineering is an effective tool for the development of corporate culture, taking into account the transformational changes in the logistics sector. The expediency of using D. Denison's model for diagnosing the condition and carrying out the procedure of reengineering the corporate culture of employees of logistics companies is substantiated. It is shown that in the conditions of the pandemic, the corporate culture has significantly expanded its external horizon of business communications and now reflects not only the ethics /professionalism /quality service of employees towards customers, but also corporate social responsibility. The concept called "Compliance» is revealed, which integrates the corporate culture, as well as the ethics of internal and external business communications.

Keywords: logistics company; corporate culture; COVID-2019 pandemic; reengineering; business communications; corporate social responsibility.

\author{
Девлетов Олег Усманович \\ К.и.н., дочент, Институт экономики и культуры, \\ 2. Санкт-Петербург \\ oleg-devletov@mail.ru \\ Гвоздева Кристина Игоревна \\ старший преподаватель, Московский \\ политехнический университет \\ gvozdevaki@mail.ru \\ Сазбандян Тамара Валерьевна \\ К.ф.н., доцент, Институт экономики и культуры, \\ г. Санкт-Петербург \\ tamojan@mail.ru
}

Аннотация: Проведенный в статье описательный анализ изменений на рынке логистических услуг, обусловленный глобальной пандемией, позволил установить тренды, которые будут определять деятельность логистических компаний в дальнейший период с неопределёнными темпоральными рамками, а также в постпандемический период. Показано, что такие изменения требуют адекватной трансформации корпоративной культуры сотрудников, которая оказывает значительное влияние на стабильность и постоянство функционирования предприятия в быстро меняющихся рыночных требованиях. Определено, что эффективным инструментом развития корпоративной культуры с учетом трансформационных изменений сферы логистики является реинжиниринг. Обоснована целесообразность использования модели Д. Денисона для диагностики состояния и проведения процедуры реинжиниринга корпоративной культуры сотрудников логистических компаний. Показано, что в условиях пандемии корпоративная культура существенно расширила свой внешний горизонт деловых коммуникаций и теперь отражает не только этику/профессионализм/качественный сервис сотрудников по отношению к клиентам, но и корпоративную социальную ответственность. Раскрыта концепция под названием «Комплаенс», которая интегрирует в себе корпоративную культуру, а также этику внутренних и внешних деловых коммуникаций.

Ключевые слова: логистическая компания; корпоративная культура; пандемия COVID-2019; реинжиринг; деловые коммуникации; корпоративная социальная ответственность.

В недавно опубликованном исследовании K. Li (2020) обобщено влияние глобальной пандемии на результаты деятельности различных предприятий и доказана гипотеза о том, что компании с сильной корпоративной культурой имеют лучшие экономические показатели, поскольку руководители и сотрудники таких компаний имеют возможность принимать последовательные решения, основанные на долгосрочной перспективе и ценностях компании [5, с. 51]. По сути, это подтвердило выводы многих исследователей о важности проблемы управления развитием корпоративной культуры предприятия в условиях динамических изменений, поддерживая при этом стабильность организации в условиях 
меняющегося внешнего мира [3, с. 230].

Целью исследования является определение влияния глобальной пандемии на деятельность поставщиков логистических услуг, зарождение новых трендов в области корпоративной культуры, а также разработка рекомендаций по диагностике и проведению процедуры реинжиниринга корпоративной культуры логистических компаний.

Основная часть. Реалии требуют от логистической отрасли гибкости и оперативного приспособления к новым быстро меняющимся условиям. В структуре корпоративной культуры внимание перешло, с одной стороны, безопасности и охране здоровья сотрудников и подрядчиков, а с другой, обеспечению непрерывности деятельности и оказанию услуг на максимально высоком уровне. Массовое эмоциональное напряжение сотрудников было вызвано беспрецедентными ограничениями, связанными с организацией их работы. Это стало испытанием для менеджеров, которым приходилось налаживать коммуникации с персоналом, работающим удаленно, и обеспечивать самые высокие стандарты безопасности для тех, кто остался на своих рабочих местах - водителей и работников склада. Результаты опроса относительно уровня вовлеченности персонала, проведенного во время пандемии, показали, что работники высоко оценивают тот факт, что об их безопасности позаботились. Они также довольны постоянным общением со своими руководителями и командой (несмотря на расстояние) и плавной корпоративной адаптацией к новой ситуации. Ограничения оказались вдохновением для поиска новых решений в области развития корпоративной культуры [9, с. 26].

Глобальная пандемия нарушила стандартные деловые коммуникации и отношения между поставщиками, производителями и потребителями и обусловила необходимость радикальных перемен в организации логистической деятельности и функционировании логистических систем и цепей поставок. Проведенный анализ деятельности поставщиков логистических услуг в условиях глобальной пандемии позволяет констатировать, что отмеченные трансформации привели к существенным изменениям в кадровой политике многих логистических компаний. С одной стороны, они переводили своих работников на удаленную форму работы, что, соответственно, стимулировало попытки оптимизировать и автоматизировать бизнес-процессы. С другой стороны, широкое использование современных информационно-коммуникационных технологий и интернета в логистической деятельности побудило компании к разработке программ повышения уровня компетентности персонала и его адаптации к изменениям на рынке логистических услуг, поскольку существует тесная связь между результативностью реализации персоналом транс- формационных изменений и корпоративной культурой предприятия - именно она является эффективным инструментом управления в кризисных условиях и только с её помощью отражается имидж компании и совокупность ценностей, норм, правил, традиций и принципов, по которым строятся все отношения компании как с сотрудниками, так и со стейхолдерами [8, с. 66].

По нашему мнению, возникла актуальная необходимость реинжиниринга корпоративной культуры логистических компаний в условиях COVID-2019 и рыночных трансформаций, который должен быть направлен на повышение уровня мотивации работников к продуктивной и результативной работе и создание конкурентных преимуществ предприятия на рынке логистических услуг. Ведь в любой компании, какую бы нишу на рынке она ни занимала и сколь бы большой она ни была, ключевое значение для успешной деятельности имеет коллектив, его ценности и идеалы. Именно команда определяет все, что собой представляет организация. Поэтому поддержание корпоративной культуры позволяет компании двигаться в одном направлении как единое целое, исповедуя общие ценности, нормы и правила.

Корпоративная культура в кризисной ситуации становится ключевым средством управления так как она может оказывать влияние на:

- мотивацию сотрудников в сложных условиях пандемии;

- привлекательность фирмы как работодателя, что отражается в таком показателе, как «текучесть кадров», которая стала очень высокой с начала распространения COVID-2019 в тех коллективах, которые не были сплочёнными;

- нравственность каждого сотрудника, его деловую репутацию;

- производительность и эффективность трудовой деятельности в условиях вынужденного дистанцирования [8, с. 63];

- качество работы сотрудников;

- характер личностных и производственных отношений в организации;

- отношение к работе; творческий потенциал кадрового персонала.

На сегодняшний день существует множество методических подходов к формированию, развитию и укреплению корпоративной культуры и большинство из них решает частные задачи реинжиниринга корпоративной культуры в кризисных условиях.

По нашему мнению, одну из наиболее репрезентативных моделей трансформации корпоративной культуры с точки зрения организационной эффективности разработал Д. Денисон. В основе модели лежит поведенческий подход с акцентом на личностные особен- 
ности, ценности и ожидания работников компании. Особенностью модели Д. Денисона является то, что она построена на оценке четырех основных характеристик корпоративной культуры и лидерства: миссии (mission), способности к адаптации (adaptability), вовлеченности (involvement) и согласованности (consistency) [1, с. 323], что особенно актуально для логистической компании в условиях COVID-2019.

Согласно представленной модели, корпоративная культура влияет на результативность логистического бизнеса посредством четырёх ключевых моментов:

- задает направление развития и четкое представление о миссии, на основании чего определяется цель, разрабатывается стратегия и строится видение будущего. Понятная и разделенная всеми сотрудниками логистической компании миссия придает целеустремленность и значимость действиям работников;

- развивает пластичность компании - способность к адаптации определяет высокий уровень гибкости и скорости реагирования на изменения внешней среды. Адаптивность измеряется приспособлением к изменениям, повышенным вниманием к клиентам, которые тоже страдают от последствий пандемии; быстрым обучением и саморазвитием в поменявшихся условиях;

- поддерживает интерес к работе - вовлеченность определяет заинтересованность работников в своей деятельности, несмотря на все сложности. На всех уровнях управленческой иерархии сотрудники чувствуют, что вносят свой вклад в принятие решений, и чувствуют, что их деятельность напрямую связана с целями компании. Существует три характеристики вовлеченности в концепции корпоративной культуры: предоставление полномочий, ориентация на работу в команде, возможность развития;

- обеспечивает согласованность, последовательность и стабильность, что характеризуется высоким уровнем преданности сотрудников, наличием собственного метода ведения бизнеса, «выращиванием» руководителей внутри компании, четким набором этических и деловых правил касательно того, что нужно и что не нужно делать в условиях кризисного развития логистической компании.

Мы хотели бы привлечь внимание к важности анализа модели корпоративной культуры Д. Денисона в вертикальном и горизонтальном разрезах, что особенно важно для понимания её неоценимости в контексте применения в логистической компании в сложившихся условиях.

Вертикальная ось дает понятие о внешнем и внутреннем фокусах компании. Вовлеченность и взаимо- действие отражают внутреннюю динамику компании, эффективность внутрикорпоративных коммуникаций, но не дают представления об эффективности взаимодействия с внешней средой посредством деловых коммуникаций.

Адаптивность и миссия отражают взаимодействие компании с внешним окружением и влияют на объем прибыли, темпы увеличения объемов продаж и увеличение доли рынка. При осуществлении реинжиниринга корпоративной культуры очень важно выработать у персонала понимания вариативности логистических процессов и способность находить оптимальный вариант решения конкретной ситуации из множества возможных, а это означает ослабление чрезмерного контроля со стороны администрации. В ходе анализа нужно выяснить, какие процессы требуют контрольных механизмов, а в каких можно обойтись без них и этим самым увеличить ответственность работника за результаты своей работы. Также важно, чтобы сотрудники различных логистических подразделений интегрировались в единую структуру принятия решений с точки зрения оптимизации выполнения заказов потребителей [6, с.167].

Помимо вышесказанного, в условиях пандемии корпоративная культура существенно расширила свой внешний горизонт деловых коммуникаций и теперь отражает не только этику/профессионализм/качественный сервис по отношению к клиентам, но и корпоративную социальную ответственность. Так, многие крупные логистические компании посредством демонстрации своих нравственных ценностей и желания помогать обществу в кризисных условиях существенно выиграли в аспекте создания нового имиджа. В таких условиях корпоративная социальная ответственность стала неотъемлемой частью корпоративной культуры, основанной на системе ценностей. Компании подходят к данной концепции комплексно, интегрируя социальную ответственную деятельность с бизнес-стратегией. Например, в условиях пандемии, многие логистические компании занималась благотворительными перевозками, помогали медицинскому персоналу и активно поддерживали продовольственные банки. В целом логистические организации только за первые месяцы объявления пандемии помогли доставить 6 миллионов масок для лица, 250 тысяч перчаток, 100 тысяч защитных костюмов, медицинских очков и козырьков, а также 51 дыхательный аппарат и свыше 12 тысяч готовых блюд для больниц и центров помощи, мебель и оборудование для больниц и свыше 1400 паллет для продовольственных банков [9, с. 26].

Помимо этого, «экологичность» теперь тоже отражает внешний фасад корпоративной культуры. Например, крупная логистическая компании «Рабен», заботясь о более благоприятном и экологическом будущем проводит кампанию «е-invoice $=$ higher culture» (электронный 
счет = высшая культура), которая поощряет клиентов использовать электронный документооборот, предлагая высадить деревья от имени тех клиентов, которые решили перейти на электронную систему. Всего на сегодняшний день компания высадила почти 16000 деревьев, что позволило нейтрализовать около 12000 тонн CO2 за их жизненный цикл. Более того, заботясь о природной среде, «Рабен» постепенно изымает бумагу из своих логистических процессов с помощью таких проектов, как Order-2-Cash или Paperless. Группа также подписала свои первые контракты на поставку зеленой энергии в 2022 году. По подсчетам, это приведет к уменьшению выбросов углекислого газа в примерно на $80 \%$ по сравнению с предыдущим годом, принимая во внимание все объекты компании [2, с. 130]. Как мы видим, расширение понятия корпоративная культура может играть существенную роль в имидже логистической компании и повышать её привлекательность для клиентов через «человеческий фактор».

Помимо вышесказанного, мы наблюдаем максимальное расширение границ понятия корпоративная культура - многие зарубежные исследователи интегрировали его в общую концепцию под названием «Комплаенс» [4, с. 680]. Для подавляющего большинства крупных организаций «Комплаенс» включает:

- кодекс корпоративной этики или корпоративного поведения, который устанавливает моральноэтические принципы, стандарты поведения, приоритеты компании и обязанности сотрудников;

- политику честной конкуренции, что требует от каждого сотрудника выполнения конкурентных правил и условий и направлена на формирование свободного рынка и открытой конкуренции товаров и услуг;

- политику внутренней и внешней «корпоративной честности» - противодействию отмыванию доходов, полученных преступным путем, защиту легального сектора экономики от проникновения теневых доходов;

- открытую политику получения и предоставления подарков, приглашений, что обеспечивает обособление понятий «подарок» и «взятка» путем установления предельной стоимости подарков и процедур контроля над их предоставлением;

- политику информирования о нарушениях этических стандартов, что дает возможность сотрудникам, заказчикам и поставщикам как официально, так и анонимно сообщать о случаях нарушения норм и стандартов поведения;

- политику, которая регулирует все аспекты деловых коммуникаций и исключает возникновение конфликта интересов благодаря внедрению этических стандартов поведения сотрудников в случае возникновения подобных конфликтов (например, в случае, когда интересы сотрудника вступают в противоречие с интересами компании, интересы одного клиента с интересами другого и т.д.);

- политику защиты сотрудников компании, что распространяется как на материальные, так и нематериальные ценности, обеспечивает защиту здоровья, «ноу-хау», интеллектуальных прав;

- политику конфиденциальности информации, которая гарантирует неразглашение информации о клиентах, регулирует хранение и обработку персональных данных, предоставление корректной отчетности [4, с.680].

Для реализации вышеуказанных политик выстраиваются рабочие процессы, которые предусматривают контроль за всеми направлениями внешних и внутренних деловых коммуникаций для выявления потенциальных проблем и их быстрого решения в режиме реального времени. Мониторинг контрагентов и лиц, с которыми осуществляются деловые контакты, предполагает также оценку степени их способности к подрыву репутации

Заключение. Проведенный описательный анализ изменений на рынке логистических услуг, обусловленный глобальной пандемией, позволил установить тренды, которые будут определять деятельность логистических компаний в дальнейший тяжёлых период с неопределёнными темпоральными рамками, а также в постпандемический период.

Показано, что такие изменения требуют адекватной трансформации корпоративной культуры, которая оказывает значительное влияние на стабильность и постоянство функционирования предприятия в быстро меняющихся рыночных требованиях. Определено, что эффективным инструментом развития корпоративной культуры с учетом трансформационных изменений сферы логистики является реинжиниринг. Обоснована целесообразность использования модели Д. Денисона для диагностики состояния и проведения процедуры реинжиниринга корпоративной культуры логистических компаний.

В условиях пандемии корпоративная культура существенно расширила свой внешний горизонт деловых коммуникаций и теперь отражает не только этику/профессионализм/качественный сервис по отношению к клиентам, но и корпоративную социальную ответственность. Так, многие крупные логистические компании посредством демонстрации своих нравственных ценностей и желания помогать обществу в кризисных условиях существенно выиграли в аспекте создания нового имиджа; зарубежные исследователи интегрируют современную корпоративную культуру и этику внешних и внутренних деловых коммуникаций в общую концепцию под названием «Комплаенс», которая получает своё развитие в трудах зарубежных учёных. 


\section{ЛИТЕРАТУРА}

1. Denison D.R., Haaland S., Goelzer P. Corporate culture and organizational effectiveness: is there a similar pattern around the world? // Advances in global leadership. - Emerald Group Publishing Limited, 2003. - C. 320-325.

2. García-Granero E.M., Piedra-Muñoz L., Galdeano-Gómez E. Measuring eco-innovation dimensions: The role of environmental corporate culture and commercial orientation // Research Policy. - 2020. - T. 49. - №. 8. - C. 104-148.

3. Hickman C.R., Silva M.A. Creating excellence: Managing corporate culture, strategy, and change in the new age. - Routledge, 2018. - $520 \mathrm{C}$.

4. Islam M.S., Tseng M.L., Karia N. Assessment of corporate culture in sustainability performance using a hierarchical framework and interdependence relations // Journal of cleaner production. - 2019. - T. 217. - C. 676-690.

5. Li K. et al. The role of corporate culture in bad times: Evidence from the COVID-19 pandemic //Journal of Financial and Quantitative Analysis. - 2020. - C. 1-68.

6. Габидуллина Г.Р., Свирская Е.В., Валеева Л.А. Развитие механизмов управления корпоративной культурой в условиях преодоления глобального кризиса, вызванного COVID-19 // Экономика и управление: научно-практический журнал. - 2021. - №. 3. - С. 166-169.

7. Гимельштейн Е.А., Годван Д.Ф. Логистика на карантине: пандемия Сovid-19 и мировой логистический кризис // Логистика -евразийский мост. - 2020. C. $277-279$.

8. Лымарева 0.А., Жукова Н.Е., Степановская Е.А. Инструменты формирования корпоративной культуры для удаленных сотрудников // Экономика устойчивого развития. - 2020. - №. 3. - С. 65-68.

9. Насонов А.Л. Логистические проблемы в условиях пандемии // Научный диалог: Экономика и менеджмент. - 2020. - С. 25-37.

( С Девлетов Олег Усманович (oleg-devletov@mail.ru), Гвоздева Кристина Игоревна (gvozdevaki@mail.ru), Сазбандян Тамара Валерьевна (tamojan@mail.ru).

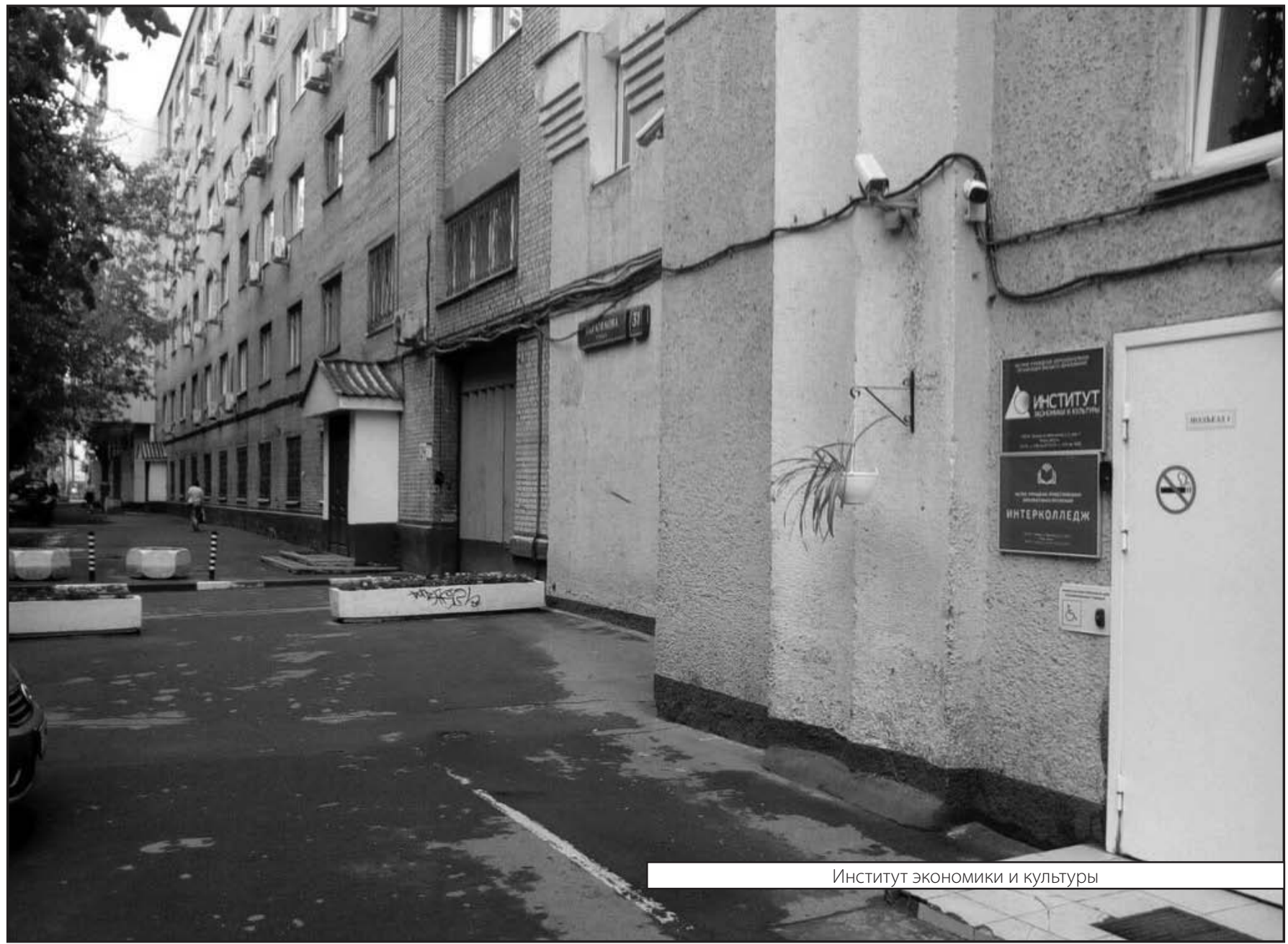

